\title{
EFEKTIVITAS TERAPI MUSIK DALAM MENURUNKAN KECEMASAN, TEKANAN DARAH DAN PERNAPASAN ANAK SETELAH OPERASI
}

\author{
Kustiningsih \\ ${ }^{1}$ Fakultas Ilmu Kesehatan Universitas Aisyiyah Yogyakarta \\ Email: kustiningsih_ning@yahoo.com
}

\begin{abstract}
Abstrak
Latar belakang: Prosedur pembedahan memicu kecemasan dan respons fisiologis seperti peningkatan frekuensi nadi dan pernapasan. Salah satu terapi pelengkap untuk meminimalkan efek tersebut adalah dengan mendengarkan musik.

Tujuan: penelitian ini adalah untuk mengidentifikasi dampak terapi musik dalam mengurangi kecemasan, frekuensi nadi, dan respirasi di antara anak-anak pasca operasi.

Metode: Penelitian ini menggunakan desain kuasi eksperimental dengan tes pre-post tanpa pendekatan kontrol. Sampel penelitian adalah 17 responden yang dipilih berdasarkan teknik consecutive sampling. Terapi musik diberikan melalui audio visual dan diberikan terus menerus selama 20 menit. Pengukuran kecemasan menggunakan metode VAS (Visual Analog Scale), dan frekuensi nadi serta respirasi diukur selama 60 detik dengan stopwatch analog.

Hasil \& Kesimpulan: Penelitian menunjukkan bahwa terdapat perbedaan yang bermakna antara ratarata kecemasan, frekuensi nadi, dan respirasi pada anak pasca operasi sebelum dan sesudah diberikan terapi musik (nilai $\mathrm{p}<0,05$ ). Terapi musik efektif dalam mengurangi kecemasan, frekuensi nadi, dan pernapasan pada anak-anak pasca operasi.
\end{abstract}

Kata kunci: kecemasan, frekuensi nadi, pernapasan, anak-anak, terapi musik, pasca operasi

\begin{abstract}
Background: Surgery procedure triggers anxiety and physiological response like the increase of pulse frequency and respiration. One of complementary therapy to minimize those effects is by listening to music.

Objective: This study was to identify the impact music therapy in decreasing the anxiety, pulse frequency, and respiration among post surgery children.

Methods: The study employed quasi experimental design with pre-posttest without control approach. The samples of the study were 17 respondents who were chosen based on consecutive sampling technique. Music therapy was given through audio visual and was given continuously during 20 minutes. Anxiety measurement used VAS (Visual Analog Scale) method, and pulse frequency and respiration were measured during 60 seconds with analog stopwatch.

Result \& conclusion: This study showed that there was meaningful different among the mean of anxiety, pulse frequency, and respiration on post surgery children before and after being given music therapy ( $\mathrm{p}$ value $<0.05$ ). Music therapy is effective in decreasing anxiety, pulse frequency, and respiration on post surgery children.
\end{abstract}

Keywords: anxiety, pulse frequency, respiration, children, music therapy, post surgery

\section{Pendahuluan}

Operasi adalah tindakan pembedahan dengan cara membuat insisi pada bagian tubuh, diakhiri dengan menutup dan menjahit luka (Smeltzer \& Bare, 2013), pada kondisi yang tidak mungkin disembuhkan dengan obat-obatan sederhana (Potter \& Perry, 2013). Operasi untuk anak-anak, merupakan tindakan yang bisa memicu respon nyeri, stres, dan kecemasan.

Kecemasan adalah emosi yang ditandai dengan perasaan tidak nyaman, takut akan suatu peristiwa dan dapat dikaitkan dengan respon tubuh dalam bentuk stimulasi simpatik, 
parasimpatis dan endokrin. Kecemasan muncul saat awal direncanakan operasi dan meningkat pada pelaksanaan operasi, bahkan setelah prosedur operasi (Baghele, Dave, Dias \& Shah, 2019). Anak-anak yang menjalani operasi lebih dari 50-75\% diantaranya dilaporkan mengalami kecemasan (Aranha, Sams \& Saldanha, 2017).

Kecemasan lebih diakibatkan karena jenis prosedur bedah, rasa nyeri, kehilangan kontrol, takut kematian dan ketidakmampuan setelah operasi. Kondisi perawatan di rumah sakit dan tim tenaga kesehatan juga ikut berkontribusi dalam meningkatkan kecemasan pada anak. Kondisi ini juga berpengaruh pada berubahnya respon fisiologis tubuh seperti meningkatnya nadi dan pernapasan serta peningkatan penggunaan analgetik pada periode awal pasca operasi, yang berdampak pada kesembuhan anak setelah operasi (Karakul \& Bolisik, 2018).

Pemilihan terapi komplementer perlu diterapkan oleh perawat untuk mendukung perawatan pasien dan meningkatkan kualitas hidup. Terapi modalitas/ komplementer akan mengaktifkan persepsi sensorik sehingga memberikan efek relaksasi, mengurangi indikator fisiologis seperti denyut nadi, tekanan darah dan pernapasan. Efek relaksasi juga bermanfaat dalam mencegah gangguan tidur, rasa sakit dan kecemasan. Salah satu terapi komplementer adalah musik (Vaajoki, Pietila, Kankkune, \& Julkunen, 2013).

Terapi musik, distraksi, dan hypnosis merupakan pendekatan non farmakologis yang memungkinkan dipergunakan untuk mengurangi kecemasan (Slater, Cornelissen, \& Fabrizi, 2010). Musik bisa menurunkan frekuensi denyut jantung, mengurangi kecemasan dan depresi, menghilangkan nyeri, dan menurunkan tekanan darah (Potter \& Perry, 2013). Musik yang akrab didengar dan sesuai dengan selera, akan menimbulkan kenyamanan, mengurangi kecemasan, meredakan depresi, meningkatkan suasana hati, membantu perawatan medis yang lebih pendek di rumah sakit, menurunkan tekanan darah, dan menghilangkan rasa sakit selama dan setelah operasi (Putri, 2012).

Penelitian dilakukan di RSUP Dr Sardjito Yogyakarta, bangsal khusus bedah anak IRNA I Ruang Cendana 4, dari tanggal 9-23 Desember 2014. Ruang Cendana 4, selalu terisi penuh oleh pasien anak dengan berbagai macam kasus bedah anak. Lama perawatan rata-rata delapan hingga sembilan hari, dengan rentang waktu terpendek empat hari hingga dua bulan. Adanya respon kecemasan anak menghadapi operasi dan belum pernah diterapkannya pemberian terapi musik untuk perawatan pasca operasi, membuat peneliti tertarik untuk melakukan penelitian. Tujuan dari penelitian ini adalah mengetahui apakah pemberian terapi musik bisa menurunkan kecemasan, nadi dan pernapasan anak pasca operasi. 


\section{Metode Penelitian}

Desain dalam penelitian ini adalah quasi experiment dengan pendekatan pre-post test without control. Sampel dalam penelitian berjumlah 17 responden yang dipilih berdasarkan teknik consecutive sampling. Kriteria inklusi dalam penelitian meliputi: bersedia menjadi responden, usia 5-13 tahun, post opersi dengan anestesi umum (General Anesthesia/ GA), dirawat hari ke dua post operasi, mendapatkan terapi analgetik dalam rentang waktu 6 jam pertama, kesadaran compos mentis, tidak mempunyai gangguan pendengaran dan pengelihatan. Kriteria eksklusi dalam penelitian adalah anak diberikan analgetik secara IV per drip. Terapi musik diberikan kontinyu selama 20 menit, dengan pilihan lagu anak-anak. Pengukuran kecemasan, dilakukan dengan VAS (Visual Analog Scale), frekuensi nadi dan pernapasan (respiratory rate) (RR) diukur selama 60 detik dengan stopwatch analog. Analisis data untuk melihat pengaruh terapi musik terhadap kecemasan, nadi dan pernapasan anak post operasi sebelum dan setelah pemberian terapi musik digunakan analisis dependent sample t-test/paired t-test.

\section{Hasil Penelitian}

Tabel 1. Distribusi Responden Berdasarkan Umur Di RSUP Dr Sardjito Yogyakarta ( n: 17 )

\begin{tabular}{ccccc}
\hline Variabel & Mean & SD & N & Min-Mak \\
\hline Umur & 8,45 & 3,20 & 17 & $5-13$ \\
\hline
\end{tabular}

Tabel 1. menunjukkan usia responden dalam penelitian minimal 5 tahun dan maksimal 13 tahun dengan rata-rata usia responden secara keseluruhan adalah 8,45 tahun. 
Tabel 2. Distribusi Responden Berdasarkan JK, Diagnosa Penyakit, Nama Pembedahan, Jenis Pembedahan, Nama dan Jenis Analgetik, Cara Pemberian Analgetik, dan Operasi Sebelumnya. Di RSUP Dr Sardjito Yogyakarta (n: 17)

\begin{tabular}{|c|c|c|c|c|}
\hline No & Variabel & $\mathbf{f}$ & $(\%)$ & Total $(\%)$ \\
\hline \multirow[t]{3}{*}{1.} & Jenis Kelamin & & & $17(100)$ \\
\hline & Laki-laki & 8 & 47,1 & \\
\hline & Perempuan & 9 & 52,9 & \\
\hline \multirow[t]{15}{*}{2.} & Diagnosa Penyakit & & & $17(100)$ \\
\hline & Megakolon kongenital & 1 & 5,9 & \\
\hline & Hemangioma wajah & 1 & 5,9 & \\
\hline & Hipospadia & 1 & 5,9 & \\
\hline & Striktur Uretra & 1 & 5,9 & \\
\hline & Defek luka post craniotomy koreksi fraktur & 1 & 5,9 & \\
\hline & Hidronefrosis & 1 & 5,9 & \\
\hline & Skin loss region pedis dextra & 1 & 5,9 & \\
\hline & Fraktur & 4 & 23,5 & \\
\hline & Tumor Sinus Maksilaris & 1 & 5,9 & \\
\hline & Ekspulsi VP Shunt (Hidrocephalus) & 1 & 5,9 & \\
\hline & Anus Anterior & 1 & 5,9 & \\
\hline & Stenosis Ani & $\begin{array}{l}1 \\
1\end{array}$ & 5,9 & \\
\hline & Obtruksi Usus & 1 & 5,9 & \\
\hline & Apendiksitis & 1 & 5,9 & \\
\hline
\end{tabular}

\begin{tabular}{|c|c|c|c|c|}
\hline No & Variabel & $\mathbf{f}$ & $(\%)$ & Total $(\%)$ \\
\hline 3. & $\begin{array}{l}\text { Nama Tindakan Pembedahan } \\
\text { Sigmoidestomi } \\
\text { Eksisi/ Debulling Tumor } \\
\text { Uretoplasty } \\
\text { Rotation flap } \\
\text { Nefrostomi } \\
\text { STSG } \\
\text { ORIF } \\
\text { CWL } \\
\text { Revisi VP Shunt } \\
\text { PSA } \\
\text { TCS } \\
\text { Laparotomi Eksplorasi }\end{array}$ & $\begin{array}{l}1 \\
1 \\
2 \\
1 \\
1 \\
2 \\
4 \\
1 \\
1 \\
1 \\
1 \\
1\end{array}$ & $\begin{array}{c}5,9 \\
5,9 \\
11,8 \\
5,9 \\
5,9 \\
11,8 \\
23,5 \\
5,9 \\
5,9 \\
5,9 \\
5,9 \\
5,9\end{array}$ & 17 (100) \\
\hline 4. & $\begin{array}{l}\text { Jenis Pembedahan/ Operasi } \\
\text { Mayor } \\
\text { Minor } \\
\end{array}$ & $\begin{array}{c}17 \\
0 \\
\end{array}$ & $\begin{array}{c}100 \\
0 \\
\end{array}$ & 17 (100) \\
\hline 5. & $\begin{array}{l}\text { Nama Analgetik yang dipakai } \\
\text { Novalgin } \\
\text { Ketorolac }\end{array}$ & $\begin{array}{c}10 \\
7 \\
\end{array}$ & $\begin{array}{l}58,8 \\
41,2 \\
\end{array}$ & 17 (100) \\
\hline 6. & $\begin{array}{l}\text { Jenis analgetik yang dipakai } \\
\text { Opiat } \\
\text { Non Opiat }\end{array}$ & $\begin{array}{c}0 \\
17 \\
\end{array}$ & $\begin{array}{c}0 \\
100 \\
\end{array}$ & 17 (100) \\
\hline 7. & $\begin{array}{l}\text { Cara Pemberian Analgetik } \\
\text { IV Bolus } \\
\text { Oral }\end{array}$ & $\begin{array}{c}17 \\
0\end{array}$ & $\begin{array}{c}100 \\
0\end{array}$ & 17 (100) \\
\hline
\end{tabular}

Tabel 2. menunjukkan bahwa mayoritas responden dalam penelitian ini berjenis kelamin perempuan $(52,9 \%)$, diagnosa penyakit terbanyak adalah fraktur $(23,5 \%)$, dengan tindakan operasi yang paling banyak ORIF (Open Reduction and Internal Fixation) (23,5 \%), dan semua tindakan operasi yang dilakukan termasuk jenis operasi mayor (100\%). Analgetik yang digunakan oleh responden terdiri dari Novalgin $(58,8 \%)$ dan Ketorolac $(41,2 \%)$, semua tergolong dalam jenis analgetik non opiat (100\%) yang diberikan melalui jalur IV 
(Intra Vena) bolus (100\%) dan mayoritas responden belum pernah melakukan operasi sebelumnya atau baru menjalani operasi untuk yang pertama kali $(52,9 \%)$.

Tabel 3. Rata-rata Kecemasan Responden Sebelum dan Setelah Pemberian Terapi Musik Di RSUP Dr Sardjito Yogyakarta (n: 17)

\begin{tabular}{ccccc}
\hline Variabel & Pengukuran & Mean & SD & Min-Max \\
\hline Kecemasan & Pre Terapi Musik & 6,33 & 2,16 & $1,20-10.0$ \\
& Post Terapi Musik & 2,42 & 1,03 & $0,40-4,00$
\end{tabular}

Hasil penelitian pada tabel 3. di atas, rata-rata kecemasan responden sebelum diberikan terapi musik berada pada skala 6,33, dengan respon cemas minimal pada skala 1,20 sampai maksimal pada skala 10. Setelah pemberian terapi musik rata-rata kecemasan responden turun pada skala 2,42, dengan kecemasan minimal pada skala 0,40 sampai maksimal skala 4,00 .

Tabel 4. Rata-Rata Frekuensi Nadi dan RR Responden Sebelum dan Setelah Pemberian Terapi Musik Di RSUP Dr Sardjito Yogyakarta (n: 17)

\begin{tabular}{llccc}
\hline \multicolumn{1}{c}{ Variabel } & \multicolumn{1}{c}{ Pengukuran } & Mean & SD & Min-Max \\
\hline Nadi & $\begin{array}{l}\text { Pre Terapi Musik } \\
\text { Post Terapi Musik }\end{array}$ & 82 & 9,02 & $71-101$ \\
& & 72 & 6,25 & $63-88$ \\
\hline RR & Pre Terapi Musik & & 2,95 & $22-33$ \\
& Post Terapi Musik & 28 & 2,36 & $20-27$ \\
\hline
\end{tabular}

Hasil penelitian pada tabel 4. didapatkan bahwa rata-rata denyut nadi responden sebelum diberikan terapi musik $82 \mathrm{x} /$ menit, dengan rentang nadi minimal $71 \mathrm{x} /$ menit sampai maksimal 101x/menit. Rata-rata denyut nadi responden setelah pemberian terapi musik turun menjadi $72 \mathrm{x} /$ menit, dengan nadi minimal $63 \mathrm{x} /$ menit sampai maksimal $88 \mathrm{x} / \mathrm{menit}$.

Rata-rata RR responden sebelum diberikan terapi musik 28 x/menit, dengan RR minimal 22 $\mathrm{x} /$ menit sampai maksimal $33 \mathrm{x} /$ menit. Setelah pemberian terapi musik rata-rata $\mathrm{RR}$ responden turun menjadi $23 \mathrm{x} /$ menit, dengan RR minimal $20 \mathrm{x} /$ menit sampai maksimal $27 \mathrm{x} /$ menit.

Tabel 5. Analisis Perbandingan Kecemasan Responden Sebelum dan Setelah Pemberian Terapi Musik Di RSUP Dr Sardjito Yogyakarta ( n: 17 )

\begin{tabular}{ccccccc}
\hline Variabel & Pengukuran & Mean & SD & t & $\begin{array}{c}\text { 95\% } \\
\text { CI }\end{array}$ & P value \\
\hline Kecemasan & $\begin{array}{l}\text { Pre Terapi Musik } \\
\text { Post Terapi Musik }\end{array}$ & 6,33 & 2,16 & 6,978 & $2,72-5,09$ & 0,000 \\
& & 2,42 & 1,03 & & &
\end{tabular}

Hasil penelitian pada tabel 5. didapatkan bahwa, rata-rata kecemasan responden sebelum diberikan terapi musik audio visual adalah 6,33, sedangkan setelah diberikan terapi musik rata-rata kecemasan responden turun menjadi 2,42. Hasil uji statistik menunjukkan adanya 
perbedaan yang signifikan kecemasan sebelum dan setelah pemberian terapi musik dengan $\mathrm{p}$ value $=0,000<\alpha=0,05$, artinya terapi musik berpengaruh dalam menurunkan kecemasan anak post operasi.

Tabel 6. Analisis Perbandingan Frekuensi Nadi dan RR Responden Sebelum dan Setelah Pemberian Terapi Musik Di RSUP Dr Sardjito Yogyakarta ( n: 17 )

\begin{tabular}{llccccc}
\hline Variabel & \multicolumn{1}{c}{ Pengukuran } & Mean & SD & Min-Max & $\mathbf{9 5 \%}$ CI & p value \\
\hline \multirow{2}{*}{ Nadi } & Pre Musik & 82 & 9,02 & $71-101$ & $77-86$ & 0,000 \\
& Post Musik & 72 & 6,25 & $63-88$ & $69-75$ & \\
\hline RR & Pre Musik & 28 & 2,95 & $22-33$ & $26-29$ & 0,000 \\
& Post Musik & 23 & 2,36 & $20-27$ & $22-24$ & \\
\hline
\end{tabular}

Hasil penelitian pada tabel 6. didapatkan rata-rata denyut nadi responden sebelum diberikan terapi musik audio visual $82 \mathrm{x} /$ menit, dengan nadi minimal 71x/menit sampai maksimal 101 $\mathrm{x} /$ menit. Setelah pemberian terapi musik rata-rata denyut nadi responden turun menjadi 72 x/menit, dengan nadi minimal $63 \mathrm{x} /$ menit sampai maksimal $88 \mathrm{x} /$ menit. Analisa statistik menunjukkan ada perbedaan signifikan $(\mathrm{p}=0,000)$ antara denyut nadi sebelum dan setelah pemberian terapi musik pada responden. Rata-rata RR responden sebelum diberikan terapi musik 28 x/menit, dengan RR minimal 22 x/menit sampai maksimal 33 x/menit. Rata-rata $\mathrm{RR}$ responden setelah pemberian terapi musik turun menjadi $23 \mathrm{x} /$ menit, dengan RR minimal $20 \mathrm{x} /$ menit sampai maksimal $27 \mathrm{x} /$ menit. Analisa statistik menunjukkan ada perbedaan signifikan $(\mathrm{p}=0,000)$ antara $\mathrm{RR}$ responden sebelum dan setelah pemberian terapi musik.

\section{Pembahasan}

\section{Perbandingan Kecemasan Responden Sebelum dan Setelah Pemberian Terapi Musik}

Hasil penelitian didapatkan rata-rata kecemasan responden sebelum intervensi musik adalah 6,33 sedangkan rata-rata kecemasan setelah intervensi musik 2,42. Uji statistik menunjukkan ada perbedaan signifikan kecemasan sebelum intervensi dan setelah intervensi terapi musik ( $\mathrm{p}$ value $=0,000)<0,05$, artinya terapi musik berpengaruh signifikan dalam menurunkan kecemasan anak usia sekolah pasca bedah.

Penelitian ini sejalan dengan hasil penelitian Karakul \& Bolisik (2018), dimana terjadi penurunan kecemasan anak pasca operasi yang diberikan terapi musik dibandingkan dengan anak yang tidak diberikan terapi musik. Penelitian lain didapatkan bahwa terapi musik klasik berpengaruh terhadap penurunan kecemasan anak usia todler (Sari \& Suryani, A (2017). Anak usia sekolah yang dilakukan hospitalisasi dengan diberikan terapi musik, juga terjadi penurunan rata2 kecemasan sebesar 4,05 dibandingkan dengan anak yang tidak diberikan terapi musik (Wahyuni, 2013). Hasil penelitian ini semakin menguatkan bahwa terapi musik sebagai terapi komplementer dan terapi adjuvant analgetik, berpengaruh signifikan dalam 
menurunkan kecemasan anak post operasi. Terapi musik terbukti menurunkan kecemasan dan pada pasien yang menjalani prosedur sigmoidoskopi dan berpengaruh signifikan dalam mengurangi kecemasan pasien pre operasi di instalasi bedah RSUP H. Adam Malik Medan (Apriyani 2010, Basri \& Lingga (2019).

Pengukuran kecemasan disini menggunakan Visual Analog Scalel VAS yang mempunyai rentang penilaian kecemasan antar 0-10. Rentang nilai 0 dikatakan tidak ada kecemasan, nilai 1 - 3 dikatakan sebagai cemas ringan, nilai 4 - 6 dikatakan sebagai cemas sedang, diantara nilai 7 - 9 cemas berat, dan 10 dianggap panik atau kecemasan luar biasa (Hassyati, 2018). Hasil penelitian ini didapatkan bahwa rata-rata kecemasan anak sebelum pemberian intervensi musik ada pada skala 6,33 atau berada pada tingkat cemas sedang. Setelah pemberian terapi musik, rata-rata kecemasan anak turun pada skala 2,42 atau berada pada tingkat cemas ringan, dengan rata-rata penurunan kecemasan sebesar 3,91.

Penurunan kecemasan pasien setelah pemberian terapi musik disebabkan karena musik dapat memberikan stimulus pada akson-akson serabut sensori assenden ke neuronneuron Reticular Activating System (RAS). Stimulus-stimulus ini akan ditransmisikan oleh nuclei spesifik dari thalamus melewati area-area korteks serebral, sistem limbik dan sistem neuroendokrin. Pada sistem neuroendokrin, musik akan mengurangi pengeluaran katekolamin norephinefrine dari medulla adrenal. Pengeluaran katekolamin menurunkan frekuensi nadi, tekanan darah, asam lemak bebas, mengurangi konsumsi O2. Selain itu musik juga mengurangi kadar kortikosteroid adrenal, Corticotrophin Releasing Hormone (CRH) dan Adrenocorticotropic Hormone (ACTH) sehingga mengurangi stres dan menambah kenyamanan (Turner, 2011).

Kenyamanan yang holistik dalam keperawatan akan terasa bila terpenuhi kebutuhannya akan relief, ease, dan transcendence dalam konteks fisik, psikospiritual, sosiokultural, dan lingkungan. Intervensi untuk meningkatkan transendensi dapat dilakukan dengan cara meningkatkan dukungan sosial dan memperbaiki lingkungan. Sesuai dengan konseptual teori Comfort, penelitian ini telah melakukan nursing intervention dengan memberikan terapi musik. Terapi musik merupakan salah satu terapi komplementer, yang terbukti efektif mengurangi ketidaknyamanan anak dalam tingkatan relief, terhadap rasa kecemasan pada anak usia sekolah post operasi (Tomey \& Alligood, 2010).

Anak dalam penelitian ini rata-rata berusia 8,45 tahun, dengan rentang usia termuda 5 tahun sampai paling tua 13 tahun, mayoritas berjenis kelamin perempuan dan belum ada pengalaman operasi sebelumnya. Usia menjadi faktor internal penyebab kecemasan dengan dominasi kecemasan pada usia lebih muda dan gangguan cemas spontan serta episodik lebih 
banyak dialami wanita daripada laki-laki (Sundeen \& Stuart, 2015). Pengalaman operasi tidak menjamin kecemasan anak otomatis menurun pada operasi berikutnya. Saat menjalani prosedur pembedahan, yang dikhawatirkan anak adalah keadaan integritas tubuhnya dan persepsi nyeri yang diakibatkan karena luka pada tubuh (Hockenberry \& Wilson (2015). Ancaman integritas fisik dan jenis pembedahan yang dilakukan bisa memicu timbulnya kecemasan (Smeltzer dan Bare 2013, Sundeen \& Stuart, 2015).

\section{Perbandingan Frekuensi Nadi dan Pernapasan Sebelum dan Setelah Pemberian Terapi} Musik

Hasil penelitian didapatkan rata-rata denyut nadi responden sebelum diberikan terapi musik $82 \mathrm{x} /$ menit dan setelah pemberian terapi musik rata-rata denyut nadi responden turun menjadi $72 \mathrm{x} /$ menit dengan $\mathrm{p}$ value $=0,000$. Sedangkan rata-rata pernapasan (Respitaroty Rate/RR) responden sebelum diberikan terapi musik $28 \mathrm{x} /$ menit dan setelah pemberian terapi musik turun menjadi $23 \mathrm{x} /$ menit dengan $\mathrm{p}$ value $=0,000$. Artinya terapi musik efektif menurunkan frekuensi nadi dan pernapasan anak selama periode pasca operasi.

Sebuah penelitian menyebutkan dari 95 anak yang dirawat pasca operasi, berhasil menurunkan nadi, tekanan darah dan pernapasan setelah diberikan terapi musik. Penelitian lain pada anak usia 1-16 tahun, saat 24 jam post operasi jantung di PICU, secara statistik menunjukkan pengurangan heart rate dan respiratory rate anak, setelah diberikan terapi musik dibandingkan dengan anak yang tidak diberikan terapi musik (Karakul \& Bolisik, 2018). Tindakan operasi menggunakan anestesi bisa mempengaruhi tubuh salah satunya adalah hemodinamik. Anestesi yang digunakan pada anak memberikan efek mual, muntah dan perubahan hemodinamik dikarenakan ada perubahan mendadak yang ditimbulkan oleh reflek simpatis dan perubahan tekanan ektravaskuler setelah injeksi anestesi sehingga mempengaruhi denyut nadi. Anestesi dapat menyebabkan pembuluh darah mengalami pre load ventrikel atau penurunan kontraktilitas miokardium, sehingga menyebabkan pembuluh darah vasodilatasi (Sabzevari, Kianifar, \& Jafari, 2017).

Kondisi kecemasan bisa mengaktifkan jalur neural dan neuroendokrin dibawah kontrol hipothalamus dan saraf simpatis diikuti oleh sekresi simpati adrenal medular serta sistem hipothalamus pituary sehingga mengakibatkan frekuensi jantung meningkat, nafas dangkal dan cepat, ketegangan otot leher, bahu dan punggung (Brunner and Suddarth, 2013). Terapi musik merupakan salah satu metode alternatif terapi komplementer yang dapat dilakukan untuk menurunkan respon kecemasan, nadi dan pernapasan anak saat operasi. Terapi musik adalah teknik penyembuhan dengan menggunakan bunyi atau irama tertentu, diutamakan musik yang familiar dan nyaman didengarkan. Pemberian terapi musik dapat 
dilakukan dengan berbagai metode, mulai dari mendengarkan kaset pilihan, menyanyikan, memainkan sebuah instrument musik yang disukai, sampai mendengarkan dan melihat musik secara visual (Apriyani, 2010). Pada penelitian ini musik yang digunakan adalah musik anak yang diberiakan secara audio visual selama 20 menit.

Terapi musik terbukti menurunkan kecemasan, menurunkan frekuensi nadi dan respitarory rate karena efek terapi musik pada sistem limbik dan saraf otonom adalah menciptakan suasana rileks, aman dan menyenangkan sehingga merangsang pelepasan zat kimia gamma amino butyric acid (GABA), enkefalin dan beta endhorphin yang dapat mengeliminasi neurotransmitter rasa nyeri maupun kecemasan sehingga menciptakan ketenangan dan memperbaiki suasana hati atau mood dan efek relaksasi. Respon relaksasi yang muncul berupa penurunan nadi, otot relaksasi, mengurangi konsumsi oksigen/O2 (Tuner, 2010, Apriyani, 2010). Musik mengaktifkan sistem saraf parasimpatis dan menyebabkan penurunan tanda fisiologis seperti tekanan darah, denyut nadi dan pernapasan (Karakul \& Bolisik, 2018).

\section{Kesimpulan}

Terapi musik berpengaruh signifikan dalam menurunkan kecemasan, frekuensi nadi dan pernapasan anak dalam perawatan pasca operasi di RSUP Dr. Sardjito Yogyakarta.

\section{Daftar Pustaka}

Aranha P.R., Sams L.M., \& Saldanha P. (2017). Preoperative preparation of children. International Journal Health Allied Sci.2017:6:1-4. https://www.researchgate.net/publication/324790203_The_effect_of_music_listened_ to_during_recovery_period_after_day_surgery_on_anxiety_state_and_vital_signs_of child and_adolescent.

Apriyani, D. (2010). Pengaruh terapi musik terhadap mual muntah lambat akibat kemoterapi pada anak usia sekolah yang menderita kanker di RSUP Dr Hasan Sadikin Bandung, tesis FIK-UI tidak dipublikasi.

Basri \& Lingga D.L (2019), Pengaruh Terapi Musik Klasik Terhadap Kecemasan Pasien Pre Operasi Di Instalasi Bedah Pusat RSUP H. Adam Malik Medan, Jurnal Keperawatan Priority, Juli 2019, Volume: 2, No. 2.

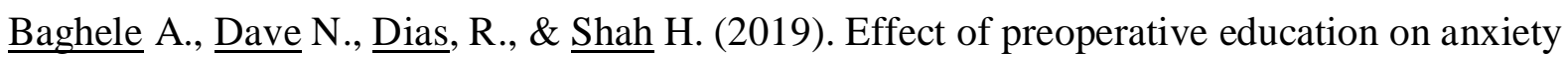
in children undergoing day-care surgery. Indian Journal Anaesthesis. 2019 Jul; 63(7): 565-570. https://www.ncbi.nlm.nih.gov/pmc/articles/PMC6644192/.

Brunner, L., \& Suddarth, D. (2013). Buku Ajar Keperawatan Medikal Bedah. Edisi 8 volume 2. Jakarta EGC. 
Hassyati, A. (2018). Hubungan Tingkat Pengetahuan dengan Tingkat Kecemasan pada Pasien Odontektomidi Klinik Gigi Joy Dental Yogyakarta. Skripsi. Yogyakarta: Poltekkes Kemenkes Yogyakarta.

Hockenberry, M., Wilson, D. (2015). Wong's nursing care of infants and children, 10th ed. USA:Elsevier.

Karakul, A. \& Bolisik, Z.B (2018). The effect of music listened to during recovery period after day surgery on anxiety state and vital signs of child and adolescent. https://www.researchgate.net/publication/324790203 The effect_of music listened to_during_recovery_period_after_day_surgery_on_anxiety_state_and_vital_signs_of child and_adolescent.

Potter, P.A., Perry, A.G., Stockert, P.A., Hall, A.M. (2013). Fundamentals of nursing. 8th ed.St. Louis, Missouri: Elsevier Mosby.

Putri, G.M. (2012). Redam cemas \& depresi dengan terapi musik, akses 9 September 2019, http://health.com/read/2012/06/21/482/651214/redam-cemas-depresi-dengan-terapimusik.

Sari, Y.K \& Suryani, A (2017), Pengaruh Pemberian Terapi Musik Klasik Terhadap Tingkat Kecemasan Anak Usia Todler Yang Mengalami Hospitalisasi Di RSUD DR.Achmad Mochtar Bukittinggi, Jurnal Kesehatan Prima Nusantara, Volume 8, No 2.

Sabzevari A, Kianifar H, Jafari SA, (2017). The effect of music on pain and vital signs of children before and after endoscopy. Electron Physician 2017;9:4801-5.

Slater, R., Cornelissen, L., \& Fabrizi, L. (2010). Oral sucrose may not reduce procedural pain in newborns. Lancet. 376(9748):1225-1232.

Smeltzer, C.S., \& Bare, G.B. (2013). Buku Ajar Keperawatan Medikal Bedah Brunner \& Suddart edisi 8. Jakarta: EGC.

Sundeen \& Stuart. (2015). Buku Saku Keperawatan Jiwa. Jakarta: EGC.

Tomey, A. M., \& Alligood, M. R. (2010). Nursing theorist and their work. St. Louis: Mosby Elsevier.

Tomey, A. M., \& Alligood, M. R. (2010). Nursing theory utilization and application. Missouri: Mosby Elsevier.

Turner, P.G., Wilson, L.L., Pryon, E.R., Boyd, L.G., \& Pricket, C.A. (2011). Perioperative music and effect on anxiety, hemodynamic, and pain in women undergoing mastectomy. AANA Journal 2011:3: 21-27.

Vaajoki A, Pietila A, Kankkune P, Julkunen K. (2013). Music intervention study in abdominal surgery patients: Challenges of an intervention study in clinical practice. International Journal Nursing Practice 2013;19:206-13. 
Wahyuni, N.S (2013), Terapi Musik Efektif Menurunkan Tingkat Kecemasan Pada Pasien Anak Usia Sekolah,https://www.researchgate.net/publication/334651700_Terapi_Musik_Efektif_ Menurunkan_Tingkat_Kecemasan_Pada_Pasien_Anak_Usia_Sekolah akses Maret 2020

Wong, Donna L, Buku Ajar Keperawatan Pediatrik Wong (6 ed.). Jakarta: EGC, 2012. 